\title{
Surveillance for foodborne diseases in a sentinel hospital in Jinhua city, Midwest of Zhejiang province, China from 2016-2019
}

\author{
Fang-Rong $\mathrm{XU}^{1}$, Yang YANG ${ }^{2 \star}$ (1)
}

\begin{abstract}
To analysis the main clinical symptoms and causative hazards of foodborne disease outbreaks to provide a reference for the prevention, control, and early warning of foodborne diseases. 2,919 FBDs cases were collected and summarised through the China Food and Drug Administration (CFDA) surveillance system. Foodborne diseases were detected according to national standards. Microsoft Excel 2010 and SPSS 12.0 were used for data descriptive analysis. The mean \pm standard deviation was used to describe the numerical variables, and the frequency and composition ratio were used to describe the classification variables. There were 2,919 FBDs cases included in the analysis. The highest number of cases occurred among students (41.49\%) and farmers (22.85\%). The months of August (398,13.63\%), September (333,11.41\%) and July (330,11.31\%) accounted for most cases. The two most frequent pathogens supported by laboratory confirmation are Norovirus and Salmonella. The major symptoms of illness were diarrhoea (97.64\%), fever (27.95\%), abdominal pain (24.67\%), vomiting (22.30\%), and nausea (13.7\%). This study revealed epidemiological characteristics of FBDs and identified some higher risk factors for interventions. Salmonella and Norovirus were the main pathogens. Foods from catering service settings and animal foods were the factors most likely to contribute to foodborne diseases. Most cases of intoxication and outbreaks were related to wild mushrooms.
\end{abstract}

Keywords: foodborne diseases; surveillance; epidemiology; risk factors.

Practical Application: This article provided clues for health education of community oriented, school oriented or other society groups.

\section{Introduction}

Foodborne diseases (FBDs) are a major public health issue worldwide, especially for young persons, older persons, and those who are sick (Fung et al., 2018). The World Health Organization (WHO) defines FBDs as 'diseases causing the infection or poisoning of human bodies, usually caused by pathogens that enter bodies through ingestion (Guo et al., 2018). In China, the most common pathogens of foodborne diseases are Dysentery bacilli, Typhoid bacilli, Salmonella, Vibrio parahaemolyticus and Escherichia coli. The peak incidence of those pathogens mentioned above is concentrated from July to September. And the peak incidence of norovirus was concentrated from November to May of the following year (Fu et al., 2019; Wu et al., 2021). Microbial contamination is an important cause of morbidity and mortality.

According to a report by the WHO, in 2010, 600 million people fell ill globally, and 420,000 people died from FBDs. The global burden FBDs caused in 2010 was 33 million disability adjusted life years(DALYs) (Havelaar et al., 2015). Internationally, one of the most notorious incidents is the Minamata disease caused by methylmercury poisoning, which, released from factories, accumulated in fish and shellfish and entered the body through consumption, first discovered in 1956 in Kumamoto Prefecture, Japan (Fung et al., 2018). Another incident occurred in the Jinzu river basin, Japan. The local residents along the river suffered an illness called 'itai-itai'. The river and crops were polluted by the sewage discharged from mining. Thus, cadmium entered the body through water and rice consumption. This caused a series of symptoms, with ostealgia as the main symptom (Fung et al., 2018).

On average, one in every 6.5 people in China suffers from FBDs due to eating unsafe food (Chen, 2016). Food safety issues are also causing concern. In 1988, an outbreak of hepatitis A occurred in Shanghai due to consumption of raw clams, which resulted in nearly 300,000 people suffering from illness, and 11 deaths (Liu et al., 2018). In 2008, consumption of melaminetainted milk had sickened more than 294,000 infants and young children, of whom 51,900 were hospitalised and resulted in at least six deaths, mainly due to kidney problems (El-Nezami et al., 2013). In 2011, in Henan province in China, many farms fed pigs with fodder mixed with clenbuterol for economic benefits. Once an anti-asthma drug, clenbuterol is banned in fodder because it brings great harm to humans through the consumption of pork (Hu et al., 2019).

Unsafe food not only affects human health and security, but also threatens economic growth and social stability.Food safety was ranked first in the top five safety issues in China (Lam et al., 
2013). In 2009, the China Food and Drug Administration (CFDA) set up the FBDs surveillance system to ensure food safety and prevent unnecessary foodborne illnesses. This included checking for pathogenic microorganisms, food products and plants entering the food supply, and chemical contamination (Wu et al., 2018). The system monitored FBDs cases, outbreaks and suspected risk factors to identify potential hazards. Zhejiang Province started the FBDs surveillance system in 2010. To date, 31 major surveillance hospitals are involved. The Affiliated Jinhua Hospital, Zhejiang University School of Medicine, as the biggest sentinel hospital in midwest Zhejiang, is among them.

Previous literature shows there were few studies from the perspective of hospitals. The objective of this study is to describe the demographic and epidemiological characteristics of FBDs surveillance carried out by Affiliated Jinhua Hospital, Zhejiang University School of Medicine during 2016-2019. Furthermore, it provided several recommendations for policy perfection and cooperation between hospitals and centres for disease control and prevention (CDC).

\section{Materials and methods}

\subsection{Case definition}

FBDs cases are defined as patients with diarrhoea (frequency equal or greater than three instances of abnormal stool characters) or vomiting or toxic symptoms suspected of being caused by food consumption. An outbreak is defined as two or more patients with FBDs who consumed the same food prior to the onset of illness at a similar time, and the clinical manifestations of all poisoned patients are basically similar.

\subsection{Data sources}

We collected and summarised data through the CFDA's surveillance system. 2,919 FBDs cases were selected in a sentinel hospital in Jinhua city from 2016-2019, and 1,651 (56.56\%) were male, while 1,268 (43.44\%) were female. The information was collected for the number of outpatients and patients hospitalised due to diarrhoea. Each patient's details included gender, age, occupation, home address, contact information, diet, duration of disease, clinical symptoms of illness, suspected food vehicle, setting of food preparation or consumption and the number of cases by suspected causative hazards. Stool samples (only from patients with diarrhoea) were collected and sent to the laboratory for confirmation, and they are mainly detected by bacterial culture and molecular biology. All the laboratory examination methods were executed in accordance with national standards (GB47894-2010, GB47895-2003, GB47897-2008 and GB478962003) and the testing procedures specified in The Manual of 2014 National Foodborne Disease Monitoring Work.

\subsection{Food vehicle classification}

Food vehicles were combined into nine classifications for clarity. For example, meat products and aquatic animal products were included in animal foods. Vegetable products, fruit products and fungi products were included in plant foods. Multiple foods refer to consuming two or more classifications of foods. Blended foods refer to a mixture of two or more classifications of foods, such as dumplings.

\subsection{Data analysis}

2,919 FBDs cases were derived from the CFDA surveillance system. SPSS12.0 were used to carry out descriptive analysis of numerical variables, frequency and composition ratio analysis of categorical variables.

\section{Results}

\subsection{Demographic distribution}

Of 2,919 FBDs cases from 2016-2019, 2,480 cases reported suspected food. The $0 \sim, 16 \sim$ and 26 age group had higher percentages. Students and farmers are high risk groups of food poisoning, accounting for $41.49 \%$ and $22.85 \%$ of the total cases, respectively. (Table 1).

\subsection{Time distribution}

The months of August $(398,13.63 \%)$, September $(333,11.41 \%)$ and July $(330,11.31 \%)$ accounted for most cases. The fewest cases occurred in the January to April period (Figure 1). The two most frequent pathogens supported by laboratory confirmation are Norovirus and Salmonella (Figure 2 and 3).

\subsection{Number of patients and hospital admissions due to diarrhoea}

From 2016-2019, the number of outpatients suffering from diarrhoea made up an average of $0.67 \%(0.53 \%-0.87 \%)$ of the total patients. The number of patients hospitalised due to diarrhoea made up an average of $0.53 \%(0.38 \%-0.74 \%)$ of the total hospitalised patients.

\subsection{Main clinical symptoms of illness}

The major symptoms of illness were diarrhoea (97.64\%), fever (27.95\%), abdominal pain (24.67\%), vomiting $(22.30 \%)$, and nausea (13.7\%). The clinical symptoms of cases are shown in detail in Table 2 and Figure 4.

\subsection{Setting of food preparation or consumption, and suspected food vehicles}

Of 2,919 FBDs cases, 2,480 patients were willing or able to provide information about food consumption in terms of food processing and packaging methods. Catering services accounted for 979 cases (39.48\%). Homemade food was the second most common method, accounting for 840 cases (33.87\%), followed by bulk food ( 273 cases, $11.01 \%$ ), other methods (229 cases, $9.23 \%$ ) and prepackaging (159 cases, $6.41 \%)$. Nine food classifications were detected. The top five were animal foods (798 cases, $32.18 \%$ ), multiple foods (405 cases, $16.33 \%$ ), plant foods ( 369 cases, $14.88 \%$ ), milk and beans (263 cases, $10.60 \%$ ) and others, mainly including lactation of human milk (303 cases, $12.22 \%$ ) (Table 3). 
Table 1. Demographic distribution of foodborne disease cases.

\begin{tabular}{|c|c|c|c|c|c|}
\hline Classification & Number of cases & Percent(\%) & Classification & Number of cases & Percent(\%) \\
\hline Gender & & & Year & & \\
\hline Male & 1651 & 56.56 & 2016 & 923 & 31.62 \\
\hline Female & 1268 & 43.44 & 2017 & 732 & 25.08 \\
\hline Age group(yr.) & & & 2018 & 677 & 23.19 \\
\hline $0 \sim$ & 732 & 25.08 & 2019 & 587 & 20.11 \\
\hline $6 \sim$ & 260 & 8.91 & & & \\
\hline $16 \sim$ & 367 & 12.57 & & & \\
\hline $26 \sim$ & 367 & 12.57 & & & \\
\hline 36 & 253 & 8.67 & & & \\
\hline $46 \sim$ & 304 & 10.41 & & & \\
\hline $56 \sim$ & 309 & 10.59 & & & \\
\hline $66 \sim$ & 327 & 11.20 & & & \\
\hline \multicolumn{6}{|l|}{ Occupation } \\
\hline $\begin{array}{l}\text { Students(include } \\
\text { preschoolers) }\end{array}$ & 1211 & 41.49 & & & \\
\hline Farmers & 667 & 22.85 & & & \\
\hline Office staff & 310 & 10.62 & & & \\
\hline Workers & 283 & 9.70 & & & \\
\hline Commercial service & 275 & 9.42 & & & \\
\hline Unemployed & 146 & 5.00 & & & \\
\hline Catering services & 10 & 0.34 & & & \\
\hline Other & 17 & 0.58 & & & \\
\hline Total & 2919 & 100 & Total & 2919 & 100 \\
\hline
\end{tabular}

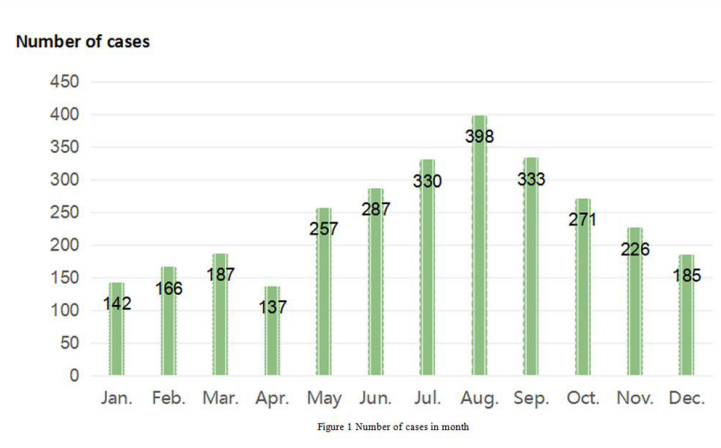

Figure 1. Number of cases in month.

\subsection{Causative hazards}

The causative hazards were classified into infectious and cases of intoxication. With decreased immunity, the human body produces less antibody synthesis. This enhances the number of infectious cases. Poisoning cases occurred due to misuse of toxic wild mushrooms and herbs or misuse of pesticides. Consuming wild mushrooms resulted in the majority of cases of intoxication and outbreaks (Table 4).

\section{Discussion}

From 2001 to 2010, 5,021 outbreaks of FBDs were reported in China, causing 140,101 illnesses and 1,427 deaths (Li et al.,
Table 2. Clinical symptoms of foodborne disease cases.

\begin{tabular}{ccc}
\hline $\begin{array}{c}\text { Main clinical } \\
\text { symptoms }\end{array}$ & Number of cases & Rate $(\%)$ \\
\hline Diarrhea & 2850 & 97.64 \\
Fever & 816 & 27.95 \\
Abdominal pain & 720 & 24.67 \\
Vomiting & 651 & 22.3 \\
Nausea & 400 & 13.7 \\
Hypourocrinia & 138 & 4.73 \\
Thirst & 61 & 2.09 \\
Dehydration & 49 & 1.68 \\
Weakness & 36 & 1.23 \\
Tic & 30 & 1.03 \\
Chills & 29 & 0.99 \\
Convulsions & 15 & 0.51 \\
\hline
\end{tabular}

2018). FBDs cause a huge burden of disease globally, especially in less developed countries. As a typical developing country, China's economy has developed rapidly since the reform and opening period. However, public health systems like food safety surveillance in China did not improve until the outbreak of SARS in 2002, which posed serious challenges. The food safety incidents mentioned above have not only heavily damaged China's food industry and exports but also done serious harm to its national reputation and international image. Worryingly, the more serious accompanying negative effects have not been completely eliminated. 


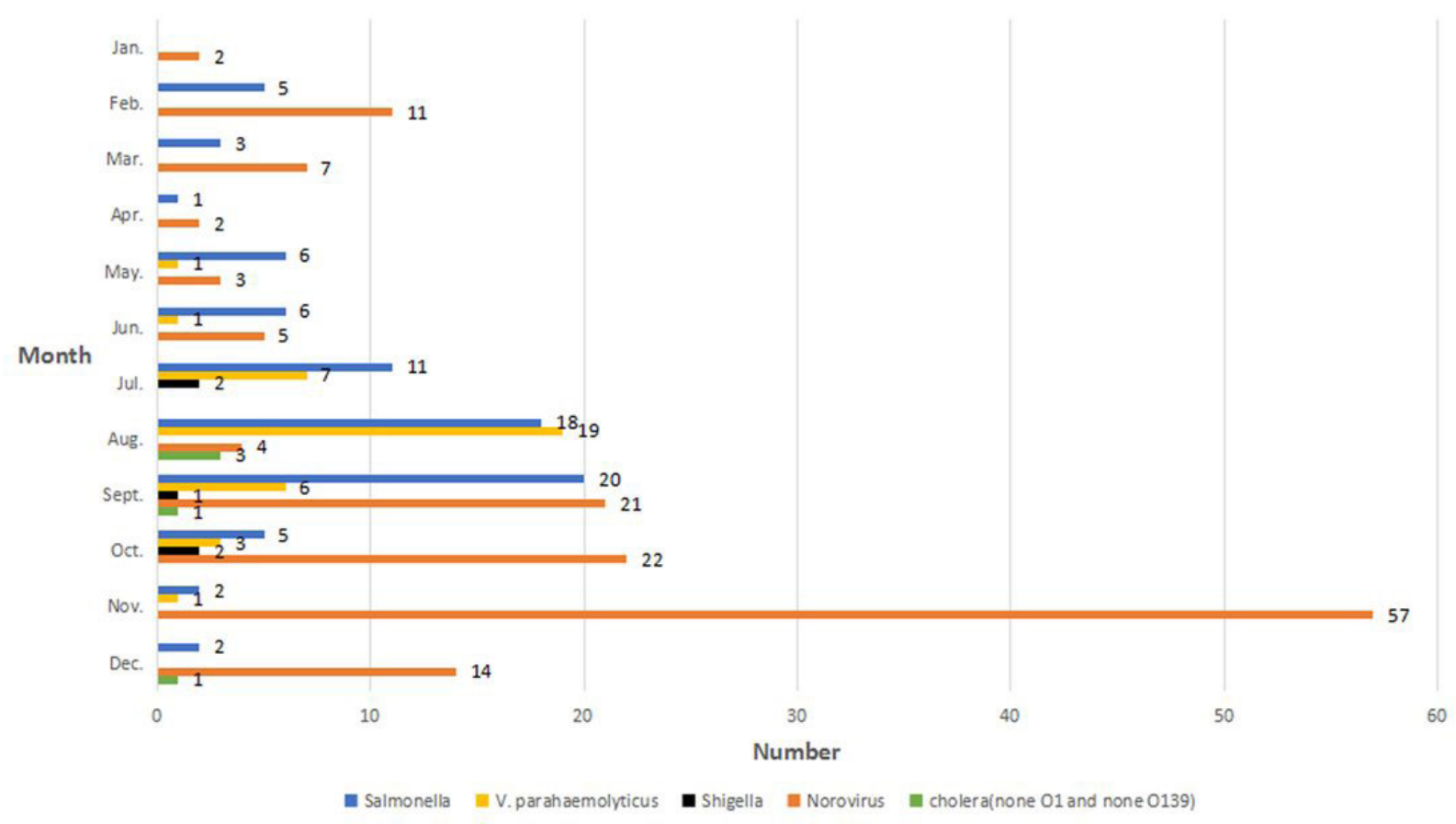

Figure 2 The laboratory confirmation in month

Figure 2. The laboratory comfirmation in month.

Table 3. Number and proportion of food preparation or consumption and vehicle.

\begin{tabular}{lcc}
\hline & $\begin{array}{c}\text { Number of } \\
\text { cases }\end{array}$ & Percent(\%) \\
\hline $\begin{array}{l}\text { Setting of food preparation or } \\
\text { consumption }\end{array}$ & \\
Catering services & 979 & 39.48 \\
Homemade & 840 & 33.87 \\
Bulk food & 273 & 11.01 \\
Prepackaging & 159 & 6.41 \\
Else ( lactation of human milk, etc) & 229 & 9.23 \\
Suspected food vehicle & & \\
Animal foods & 798 & 32.18 \\
Multiple foods & 405 & 16.33 \\
Plant foods & 369 & 14.88 \\
Milk and bean & 263 & 10.6 \\
Blended foods & 143 & 5.77 \\
Cereals & 95 & 3.83 \\
Drinks & 75 & 3.02 \\
infant foods & 29 & 1.17 \\
Else(Sweetmeat, Nut, condiment, Algae, & 303 & 12.22 \\
etc) & & \\
Total & $\mathbf{2 4 8 0}$ & $\mathbf{1 0 0}$ \\
\hline
\end{tabular}

In our study, the patients' symptoms are mainly diarrhoea, fever, abdominal pain, vomiting and nausea, as shown in other studies. Infectious cases usually have digestive symptoms of diarrhoea, abdominal pain or vomiting. As the leading symptom of FBDs, diarrhoeal disease is also one of the leading causes of death in children under five (Asefa et al., 2020). In a single

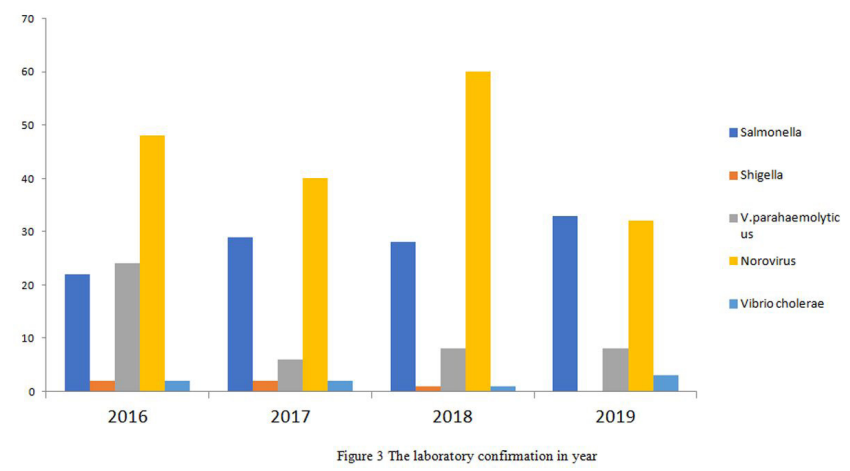

Figure 3. The laboratory comfirmation in year.

hospital like ours, within four years, 53,733 (0.67\%) outpatients seek treatment due to diarrhoea. Among these patients, 2,658 $(0.57 \%)$ were hospitalised (Table 2). This causes great health and financial burden to patients, as well as increasing doctors' workloads. Further, the risk of hospital infection could be a threat to other patients.

Males were more likely to suffer from FBDs, as men were generally more adventurous than women when making irrational decisions (Shan et al., 2019). Children under six were more likely to suffer FBDs, as mentioned in the previous study (Havelaar et al., 2015), due to their lower immunity and the absence of health education. Preschoolers and students accounted for more than $60 \%$ of cases. This is partly due to their lower immunity, as 
Table 4. Number of cases by suspected causative hazards.

\begin{tabular}{lcc}
\hline \multicolumn{1}{c}{ Causative hazards } & Number of cases & Percent $(\%)$ \\
\hline Infectious cases & $\mathbf{2 8 7 6}$ & $\mathbf{9 8 . 5 2}$ \\
Toxic cases & $\mathbf{4 3}$ & $\mathbf{1 . 4 8}$ \\
Wild mushrooms & 28 & 0.96 \\
Herb & 11 & 0.38 \\
Agaric & 2 & 0.07 \\
Pesticide & 2 & 0.07 \\
\hline
\end{tabular}

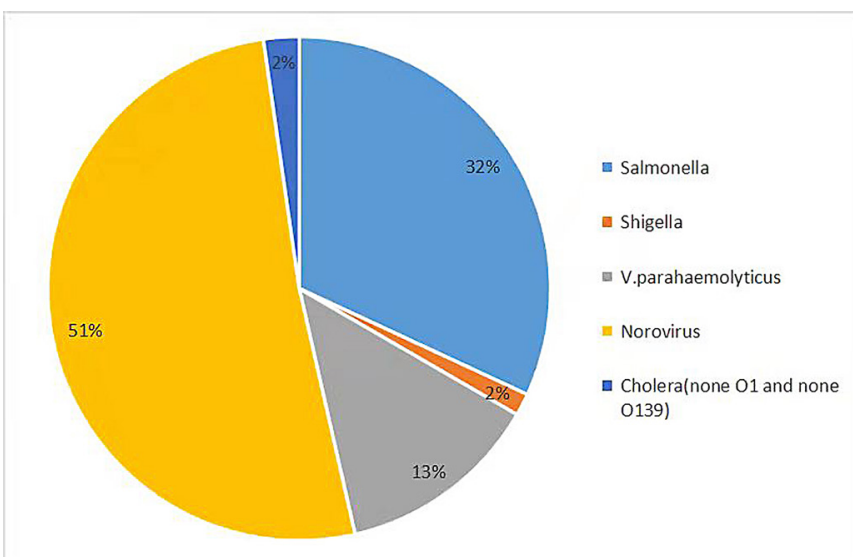

Figure 4. Pathogen constituents.

mentioned above. This is also due to their lack of control over their diets and the likelihood that they consume food at roadside stands which usually have poor sanitary conditions. Significantly, farmers made up a fifth of all cases. Compared with developed countries, most farmers in China belong to a low-income group. Therefore, they pay little attention to the food safety and hygiene and consumption settings and, thus, are more likely to be invaded by pathogens through contaminated food.

The seasonality of FBDs cases was observed in this study. Most cases occurred in warm months (May to October), peaking in summer. This was in line with other studies (Wu et al., 2021;Li et al., 2018). On the one hand, high temperatures are conducive to pathogen growth, as is known (Yang et al., 2019). On the other hand, insects such as flies multiply rapidly when the temperature is appropriate, and pathogens spread to many places, along with those hosts' movements. As showed in Figure 2, bacteria like Salmonella, V. parahaemolyticus, Shigella and cholera (none O1 and none O139) were commonly detected in warm months. However, a seasonal peak in summer does not occur for some pathogens. For instance, Norovirus is more frequent in winter months when the temperature is relatively low (Hall et al., 2012). Certainly, temperatures are not the only factors with seasonality. Humidity, light or other climatic factors could also influence pathogen growth (Park et al., 2018).

Causative hazards will invade food during each link of preservation and processing, such as food storage, food preparation, cooking, the cooking environment, the hand hygiene of cooks and pantry helpers and tableware disinfecting (Yang et al.,
2019; Brown et al., 2017). One well-known person was 'Typhoid Mary' who brought typhoid to places where she worked as a cook (Fegan \& Jenson, 2018). About $40 \%$ of patients with FBDs reported consuming food from catering service settings prior to the onset of illness. In recent years, it has become fashionable to order takeaway food through apps. This brings more unsafe factors since it is difficult to supervise the quality of food and the preparation process for those without fixed shops. In addition, due to the complexity of Chinese food and cooking methods, pathogens could contaminate foods in more ways, making it difficult to avoid FBDs. The main food vehicles suspected of causing illnesses are animal foods and multiple foods. As it is known, animal foods can provide hotbeds for pathogens if not stored properly and, thus, cause diseases (Marr, 1999). Similar to other studies (Wu et al., 2019; Finger et al., 2019), multiple foods remain one of the most common vehicles, and this presents difficulties in identifying the specific foods and preventing them from circulation. It should be noted that homemade foods led to more than $30 \%$ of cases. As shown above, $1.48 \%$ of FBDs cases and $20 \%$ of the FBDs outbreaks related to people picking wild mushrooms, herb or agaric and consuming them at home, even consuming pesticide by mistake. All of this suggested the absence of food safety education for the general public.

With globalisation, the problems of food safety will not be restricted to a single country or region. In China, a large population, environmental pollution, regional development imbalances and public health system construction remain crucial. Challenges are upon us, not merely to hospitals but also government agencies, CDC, health supervision agencies and food enterprises. Government agencies must reinforce laws to strengthen food safety. Hospitals should be on the alert for FBDs cases, provide proper treatment and share information with CDC as well as other health supervision agencies or organisations. As the source of the food supply chain, food enterprises must stick to the rules and regulation on food safety and hygiene to make people safe.

Some limitations exist in this study. First, we did not use any sequencing or genomic methodologies. The use of the power of whole genome sequencing in combination with laboratory methods in order to understand genetic differences between pathogens and to conduct surveillance of diseases. Second, a few patients failed to provide information about food consumption. It reduced the available data of food consumption characters to a degree. Third, when considering different diagnostic levels and a lack of laboratory confirmation, a small number of cases that might not be classified as FBDs were included in the study. These cases may provide some interference information for analysis. Fourthly, this study was conducted in only one hospital. In the future, we hope more hospitals in Jinhua city will join the surveillance system. The data from each hospital will be combined and be more representative of the whole city. Finally, only a few pathogens were identified by the laboratory for confirmation, resulting in some pathogens not being detected. We hope that in future, more pathogens will be included and that this will improve the rate of laboratory confirmation. Thus, suggestions from studies will be more targeted for policymakers and supervisors. In these future studies, we will make improvements according to the above limitations. 
This study revealed epidemiological characteristics of FBDs in our hospital and identified some higher risk factors for interventions. This study revealed epidemiological characteristics of FBDs and identified some higher risk factors for interventions. Males and preschool children were more likely to suffer FBDs. Salmonella and Norovirus were the main pathogens. Foods from catering services settings and animal foods were the factors that most often contribute to foodborne diseases. Most of the cases of intoxication and outbreaks were related to wild mushrooms. Some information was provided to the government and other organisations for further policy-making and supervision to ensure food safety.

\section{Ethical approval}

The study was conducted in accordance with the Declaration of Helsinki and the protocol was approved by the Ethics Committee of Affiliated Jinhua Hospital, Zhejiang University School of Medicine (2019-301).

\section{Conflict of interest}

The authors declare that they have no competing interests.

\section{Availability of data and material}

All data generated or analyzed during this study are included in this published article.

\section{Funding}

Not applicable.

\section{Author contribuitions}

These authors contributed equally to this study.

\section{Acknowledgements}

No funding or sponsorship was received for this study or publication of this article.

\section{References}

Asefa, A., Qanche, Q., Asaye, Z., \& Abebe, L. (2020). Determinants of delayed treatment-seeking for childhood diarrheal diseases in Southwest Ethiopia: a case-control study. Pediatric Health, Medicine and Therapeutics, 11, 171-178. http://dx.doi.org/10.2147/PHMT. S257804. PMid:32607050.

Brown, L. G., Hoover, E. R., Selman, C. A., Coleman, E. W., \& Rogers, H. S. (2017). Outbreak characteristics associated with identification of contributing factors to foodborne illness outbreaks. Epidemiology and Infection, 145(11), 2254-2262. http://dx.doi.org/10.1017/ S0950268817001406. PMid:28689510.

Chen, J. S. (2016). Who is the number one enemy of food safety?. Dietetic Science, 2016(5), 20.

El-Nezami, H., Tam, P. K. H., Chan, Y., Lau, A. S. Y., Leung, F. C. C., Chen, S. F., Lan, L. C. L., \& Wang, M. F. (2013). Impact of melaminetainted milk on foetal kidneys and disease development later in life. Hong Kong Medical Journal, 19(Suppl 8), 34-38. PMid:24473527.
Fegan, N., \& Jenson, I. (2018). The role of meat in foodborne disease: Is there a coming revolution in risk assessment and management? Meat Science, 144, 22-29. http://dx.doi.org/10.1016/j.meatsci.2018.04.018. PMid:29716760.

Finger, J. A. F. F., Baroni, W. S. G. V., Maffei, D. F., Bastos, D. H. M., \& Pinto, U. M. (2019). Overview of foodborne disease outbreaks in Brazil from 2000 to 2018. Foods, 8(10), 434. http://dx.doi.org/10.3390/ foods8100434. PMid:31547589.

Fu, P., Wang, L. S., Chen, J., Bai, G. D., Xu, L. Z., \& Guo, Y. C. (2019). Analysis of foodborne disease outbreaks in China mainland in 2015. Zhongguo Shipin Weisheng Zazhi, 31(01), 64-70.

Fung, F., Wang, H. S., \& Menon, S. M. (2018). Food safety in the 21st century. Biomedical Journal, 41(2), 88-95. http://dx.doi.org/10.1016/j. bj.2018.03.003. PMid:29866604.

Guo, S., Lin, D., Wang, L. L., \& Hu, H. (2018). Monitoring the results of foodborne diseases in Sentinel Hospitals in Wenzhou city, China from 2014 to 2015. Iranian Journal of Public Health, 47(5), 674-681. PMid:29922609.

Hall, A. J., Eisenbart, V. G., Etingüe, A. L., Gould, L. H., Lopman, B. A., \& Parashar, U. D. (2012). Epidemiology of foodborne norovirus outbreaks, United States, 2001-2008. Emerging Infectious Diseases, 18(10), 1566-1573. http://dx.doi.org/10.3201/eid1810.120833. PMid:23017158.

Havelaar, A. H., Kirk, M. D., Torgerson, P. R., Gibb, H. J., Hald, T., Lake, R. J., Praet, N., Bellinger, D. C., Silva, N. R., Gargouri, N., Speybroeck, N., Cawthorne, A., Mathers, C., Stein, C., Angulo, F. J., \& Devleesschauwer, B. (2015). World Health Organization global estimates and regional comparisons of the burden of foodborne disease in 2010. PLoS Medicine, 12(12), e1001923. http://dx.doi. org/10.1371/journal.pmed.1001923. PMid:26633896.

Hu, D. W., Liu, C. X., Zhao, H. B., Ren, D. X., Zheng, X. D., \& Chen, W. (2019). Systematic study of the quality and safety of chilled pork from wet markets, supermarkets, and online markets in China. Journal of Zhejiang University Science B., 20(1), 95-104. http://dx.doi. org/10.1631/jzus.B1800273. PMid:30614233.

Lam, H. M., Remais, J., Fung, M. C., Xu, L. Q., \& Sun, S. S. M. (2013). Food supply and food safety issues in China. Lancet, 381(9882), 2044-2053. http://dx.doi.org/10.1016/S0140-6736(13)60776-X. PMid:23746904.

Li, Y. Q., Huang, Y. L., Yang, J. J., Liu, Z. H., Li, Y. M., Yao, X. T., Wei, B., Tang, Z. Z., Chen, S. D., Liu, D. C., Hu, Z., Liu, J. J., Meng, Z. H., Nie, S. F., \& Yang, X. B. (2018). Bacteria and poisonous plants were the primary causative hazards of foodborne disease outbreak: a sevenyear survey from Guangxi, South China. BMC Public Health, 18(1), 519. http://dx.doi.org/10.1186/s12889-018-5429-2. PMid:29669556.

Liu, J. K., Bai, L., Li, W. W., Han, H. H., Fu, P., Ma, X. C., Bi, Z. W., Yang, X. R., Zhang, X. L., Zhen, S. Q., Deng, X. L., Liu, X. M., \& Guo, Y. C. (2018). Trends of foodborne diseases in China: lessons from laboratory-based surveillance since 2011. Frontiers of Medicine, 12(1), 48-57. http://dx.doi.org/10.1007/s11684-017-0608-6. PMid:29282610.

Marr, J. S. (1999). Typhoid mary. Lancet, 353(9165), 1714. http://dx.doi. org/10.1016/S0140-6736(05)77031-8. PMid:10335825.

Park, M. S., Park, K. H., \& Bahk, G. J. (2018). Interrelationships between Multiple Climatic Factors and Incidence of Foodborne Diseases. International Journal of Environmental Research and Public Health, 15(11), 2482. http://dx.doi.org/10.3390/ijerph15112482. PMid:30405044.

Shan, L., Wang, S. S., Wu, L. H., \& Tsai, F. S. (2019). Cognitive biases of consumers' risk perception of foodborne diseases in China: examining anchoring effect. International Journal of Environmental 
Research and Public Health, 16(13), 2268. http://dx.doi.org/10.3390/ ijerph16132268. PMid:31252539.

Wu, G., Wang, L. S., Wang, Q., Han, R., Zhao, J. S., Chu, Z. H., Zhuang, M. Q., Zhang, Y. X., Wang, K. B., Xiao, P. R., Liu, Y., \& Du, Z. J. (2019). Descriptive study of foodborne disease using case monitoring data in Shandong province, China, 2016-2017. Iranian Journal of Public Health, 48(4), 722-729. http://dx.doi.org/10.18502/ijph.v48i4.1006. PMid:31110983.

Wu, G., Yuan, Q., Wang, L. S., Zhao, J. S., Chu, Z. H., Zhuang, M. Q., Zhang, Y. X., Wang, K. B., Xiao, P. R., Liu, Y., \& Du, Z. J. (2018).
Epidemiology of foodborne disease outbreaks from 2011 to 2016 in Shandong Province, China. Medicine, 97(45), e13142. http://dx.doi. org/10.1097/MD.0000000000013142. PMid:30407341.

Wu, X., \& Xu, D., Ji, L., Zha, Y., \& Chen, L. (2021). Surveillance results of foodborne diseases in Huzhou, Zhejiang, 2018-2020. Disease Surveillance, 36(9), 958-962.

Yang, L., Sun, Y. B., Zhong, Q., Duan, D. S., Liu, S. Q., \& Zhang, Y. (2019). Epidemiological characteristics and spatio-temporal patterns of foodborne diseases in Jinan, Northern China. Biomedical and Environmental Sciences, 32(4), 309-313. PMid:31217068. 